
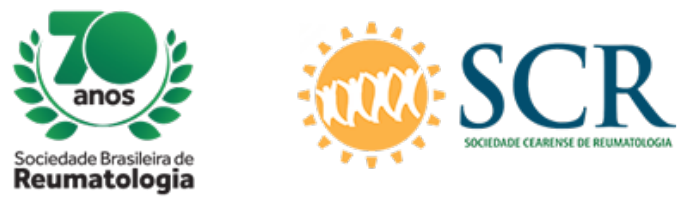

\title{
A CHRONIC TOPHACEOUS GOUT CASE TREATED WITH TREAT TO TARGET STRATEGY: CASE REPORT
} AND LITERATURE REVIEW

Paulo Esrom Moreira Catarina (Universidade Estadual do Ceará, Fortaleza, CE, Brasil), Edmara Bezerra

Guerra da Costa (Hospital Geral de Fortaleza, Fortaleza, CE, Brasil), Marla Rochana Braga Monteiro

(Universidade Estadual do Ceará, Fortaleza, CE, Brasil), Francisca Edwirges Araújo Moura (Hospital Geral de Fortaleza, Fortaleza, CE, Brasil), Kirla Wagner Poti (Hospital Geral de Fortaleza, Fortaleza, CE, Brasil), Walber Pinto Vieira (Hospital Geral de Fortaleza, Fortaleza, CE, Brasil)

\section{BACKGROUND}

Gout is the most common cause of inflammatory arthritis in adults in the world. It is characterized by the accumulation of monosodium urate in joints and any other tissue at the organism. The disease progresses after some pathophysiological stages: varying since hyperuricemia without evidence of crystal deposition until chronic or advanced tophaceous arthritis. Despite the effective treatments through urate-lowering therapy (ULT), gout is still misdiagnosed and its management is suboptimal. There are indirect evidence that highlights the benefit of using the Treat to Target strategy, which aims at obtaining predefined uric acid targets. The aim of this study is to report the case of a patient with severe chronic tophaceous gout, who have undergone a Treat to Target strategy-based therapy.

\section{CASE REPORT}

59-year-old man, freelance salesman, presented the first podagra attack on his left foot by the age of 30, evolving over the years with ever more quickly intercritical periods, by the lack of medical care, with progression to a polyarticular presentation and the emergence of difuse gouty tophi. In 2008 , he started a follow-up at the general rheumatology outpatient clinic without therapeutic success, with prescription of allopurinol, benzbromarone and colchichine, with uric acid's levels of $10,1 \mathrm{mg} / \mathrm{dL}$, by the end of a 6 years follow-up. 4 years ago (January/2015), he was admitted at a gout outpatient clinic, and underwent the Treat to Target strategy in the management of gout. Initially, he did not tolerate ULT due to recurring flares, but he kept a prophylactic treatment with colchichine and corticoid, associated to slow and progressive ULT titration, with guidance and orientation over the relevance of the therapeutic targets of uric acid, as well as frequent visits. Subsequently, in association with benzbromarone combined therapy (November/2015), it was possible to reach in 3 months the level of uric acid of $5,1 \mathrm{mg} / \mathrm{dL}$, close to the recommended target, showing flare resolution and progressive tophi reduction. By the end of 4 years and 3 months of follow-up (April/2019), he remains asymptomatic, without new acute attacks.

\section{CONCLUSION}

Although the Treat to Target strategy is widely used and well established in rheumatologic diseases, such as rheumatoid and psoriatic arthritis, it is still not often used in the global scene of gout treatment. The evolution of the patient indicates that the Treat to Target therapy is effective for relieving the disease outbursts in patients with chronic tophaceous arthritis, with great improvement in their quality of life. 